\title{
Zuhaltzoerzeidnaiß.
}

\section{Stenographithe Beridte.}

Tete

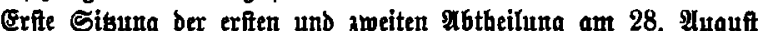

3weite Sikung ber exiten unb zweiten פrbtheilung aut 29. צugurt. 105

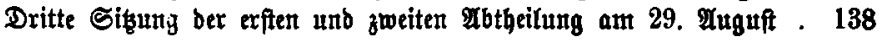

Erfte Sizung der britten झbtheilung am 28. Iuguft . . . . . 172

3weite Sikung ber britten 9btheilung am 29. Aluguft . . . . . 212

Dritte Sižzung ber britten $\mathfrak{A b t h e i l u n g ~ a m ~ 2 9 . ~ O H u g u f t ~ . ~ . ~ . ~ . ~ . ~} 259$

Erfte Sigung ber vierten आbtheilnng am 28. æuguft. . . . . 298

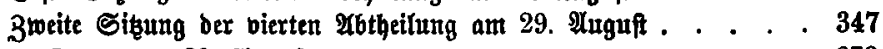

3weite Plenarfigung am 30 . Iuguft . . . . . . . . . . . . . . 373 
